Revista de

Contabilidade e

Organizações

www.rco.usp.br
DOI: http://dx.doi.org/10.11606/rco.v9i24.79534
Journal of

Accounting and

Organizations

www.rco.usp.br

\title{
Construção de métrica para avaliação da qualidade da informação contábil sob a ótica de analistas fundamentalistas
}

\author{
Josilene da Silva Barbosa ${ }^{\mathrm{a}}$; Luciano Márcio Scherer ${ }^{\mathrm{a}}$, Jorge Eduardo Scarpin ${ }^{\mathrm{a}}$; Fernando Dal-Ri Murcia ${ }^{\mathrm{b}}$ \\ ${ }^{a}$ Universidade Federal do Paraná \\ ${ }^{b}$ Universidade de São Paulo
}

\section{Informações do Artigo}

Histórico do Artigo

Recebido: 13 de abril de 2014

Aceito: 15 de julho de 2015

Palavras chave:

Qualidade da informação contábil

Validação interna e externa

Analistas fundamentalistas

Técnica Delphi

\begin{abstract}
Resumo
Este estudo objetivou construir uma Métrica de Qualidade da Informação Contábil (MQIC) sob a ótica de analistas fundamentalistas, os quais, enquanto intermediários informacionais, utilizam informações públicas para fazer suas previsões e recomendações sobre as melhores oportunidades de investimentos. Para atingir o objetivo proposto foi utilizada a técnica Delphi, mediante a aplicação de um questionário elaborado a partir da literatura sobre qualidade da informação contábil a um grupo de analistas fundamentalistas. Os resultados do estudo permitiram construir uma MQIC com 17 componentes, com nota variando entre 0 (pior nota) e 100 (melhor nota). A média geral dos 17 componentes da métrica final foi 4,3, indicando uma concordância elevada entre os analistas sobre os itens que compõem a MQIC. Além disso o Coeficiente de Variação foi $18,4 \%$ o que indica uma dispersão média dos dados. Por fim, o resultado do Alfa de Cronbach, de 0,89 , atestou que a MQIC possui consistência interna.
\end{abstract}

Copyright $(92015$ FEA-RP/USP. Todos os direitos reservados

\section{INTRODUÇÃO}

A Contabilidade tem como atribuição comunicar aos interessados informações úteis que envolvem eventos econômicos e financeiros das empresas, servindo como suporte para tomada de decisão ou investimentos (KAM, 1990). Hendriksen e Van Breda (2011) consideram que as informações contábeis devem ser divulgadas para investidores, clientes, credores, funcionários, órgãos do governo e ao público em geral. Porém, estes usuários são vistos como secundários, necessitando, segundo Iudícibus (2009), de um intermediador, conhecedor da contabilidade, para interpretar e traduzir de modo mais simples as informações. Lopes e Martins (2005) listam auditores, analistas de mercado de capitais e empresas de rating como intermediadores informacionais.

Brennan e Subrahmanyam (1995) e Irvine (2003), ao encontrarem evidências de que há associação positiva entre o acompanhamento do analista e a liquidez de mercado das ações, demonstram que os analistas de mercado são agentes capazes de influenciar a decisão dos investidores. Francis, Hanna e Philbrick (1997) sugerem que os analistas tendem a cobrir empresas com melhor ambiente de informações. Para Ball e Shivakumar (2005), haverá qualidade nas informações contábeis se estas forem úteis aos usuários. Carvalho (2012), ao utilizar a qualidade do lucro como proxy para medir a qualidade dos relatórios contábeis, constatou que má qualidade dos lucros reportados afeta negativamente as decisões de investimentos.

Biddle e Hilary (2006) explicam que informações contábeis com qualidade dificultam a ação discricionária dos gestores. Contudo, Beest, Braam e Boelens (2009) argumentam que normalmente são utilizadas medidas indiretas na mensuração da qualidade da informação, ou seja, focam em atributos específicos (gerenciamento de resultados) ou apenas em algumas das características qualitativas da informação contábil (oportunidade, conservadorismo, relevância, etc.). Além disso, Malaquias e Oliveira Neto (2011) consideram que, na construção de instrumentos de coleta de dados, seja levado em conta, por exemplo, a opinião de investidores e analistas de

Autor Correspondente: Tel (41) 33604193

E-mail : jslene_barbosa@yahoo.com.br (J. S. Barbosa); lmscherer@ufpr.br (L. M. Scherer); jscarpin@gmail.com (J. E. Scarpin); murcia@usp.br (F. D. Murcia) UFPR - Avenida Prefeito Lothario Meissner, 732, Campus III - Jardim Botânico - 80210170 - Curitiba, PR - Brasil 
mercado.

Assim, o objetivo deste estudo consistiu em construir uma Métrica de Qualidade da Informação Contábil (MQIC) por meio de evidências empíricas, teóricas e normativas sob a ótica de analistas fundamentalistas. Para tanto foi desenvolvido um estudo com um grupo de analistas fundamentalistas, com o propósito de verificar suas percepções quanto à qualidade da informação contábil.

Este estudo aborda um tema eminente e de interesse dos usuários da informação contábil, estando diretamente relacionado com os aspectos contábeis, portanto, acredita-se em sua relevância, pois seus resultados podem ajudar os tomadores de decisão e intermediadores informacionais em suas decisões de investimento. Como contribuição teórica, o estudo apresenta a construção da métrica MQIC, utilizando como especialistas analistas fundamentalistas, que são agentes conhecedores de informações contábeis.

\section{REFERENCIAL TEÓRICO}

\subsection{Evidenciação e qualidade da informação contábil}

As demonstrações contábeis são a principal fonte de comunicação contábil, as quais buscam oferecer de forma sintética, melhor compreensão dos fatos organizacionais (TAKAMATSU; LAMOUNIER; COLAUTO, 2008). De acordo com o Pronunciamento Técnico CPC 00 R1, elas são elaboradas e apresentadas para usuários internos e externos, tendo em vista suas finalidades distintas e necessidades diversas, uma vez que quase todos eles as utilizam para a tomada de decisões. Iudícibus (2009) argumenta que o sentido da evidenciação é omitir as informações não relevantes, a fim de tornar as demonstrações contábeis significativas e possíveis de serem plenamente compreendidas.

De acordo com Silva (2009, p. 18), a teoria da divulgação aborda os aspectos associados à divulgação de informações financeiras sob várias perspectivas, entre elas verificar o efeito da divulgação de demonstrações contábeis no preço das ações e explicar as razões econômicas para o disclosure voluntário. Dye (2001) acredita que a teoria da divulgação contábil possui estágio desenvolvido, ao passo que Verrecchia (2001) argumenta que não há uma teoria da divulgação abrangente ou unificada, de forma que, para ele, não haveria nenhum paradigma central sobre a teoria de divulgação, e nem mesmo integração entre as teorias.

Desse modo, Verrecchia (2001) propõe uma categorização das pesquisas sobre divulgação contábil em três grupos. No primeiro ele se refere às pesquisas sobre Divulgação Baseada em Associação, que buscam investigar a associação entre divulgação e comportamento dos investidores, com o foco sendo a investigação do comportamento dos preços dos ativos e da volatilidade dos negócios. A seguir, há as pesquisas sobre Divulgação Baseada em Julgamento, cujo objetivo é identificar os motivos da divulgação, considerando-se, nesse caso, a divulgação voluntária como processo endógeno. E por fim, as pesquisas sobre Divulgação Baseada em Eficiência englobam os estudos sobre os aspectos de eficiência da informação, ou seja, nesse momento a divulgação ainda não ocorreu (ex ante).

Beyer et al. (2010) citam que a divulgação de informações por parte das empresas ocorre em função da obrigatoriedade exigida pelos órgãos reguladores e também de forma voluntária. Neste último caso a empresa decide divulgar determinada informação que será útil à tomada de decisão dos usuários, oferecendo maior transparência, se isso de alguma forma lhe beneficiar.

A informação contábil possui relevância no mercado de capitais por influenciar as decisões de investimentos (YAMAMOTO; SALOTTI, 2006). O analista de mercado, como intermediário informacional, utiliza as informações disponibilizados ao público para fazer suas previsões e recomendações, mostrando as melhores oportunidades de investimentos (HEALY; PALEPU, 2001). Porém, suas análises dependem de fatores como disponibilidade, atualidade, formato; integridade (BOFF; PROCIANOY; HOPPEN, 2006) e precisão da informação publicada (FISCHER; STOCKEN, 2010) e por isso estes agentes tendem a cobrir empresas com maior nível de qualidade da informação (FRANCIS; HANNA; PHILBRICK, 1997).

Biddle e Hilary (2006) afirmam que demonstrações contábeis com alta qualidade aumentam a eficiência nos investimentos devido a sua capacidade de alterar o comportamento discricionário dos gestores. Os achados de Carvalho (2012) contribuem com essa afirmativa, pois, mostram que má qualidade dos lucros reportados afeta negativamente as decisões de investimentos. Francis et al. (2004), comprovam que melhor qualidade nas 
informações financeiras reduz o custo de capital próprio.

Ball e Shivakumar (2005) mencionam que a informação contábil deve ser útil aos tomadores de decisões. No parágrafo QC3 do Pronunciamento Técnico CPC 00 R1, como forma de garantir a utilidade da informação contábil, é estabelecido que "as características qualitativas [...] devem ser aplicadas à informação contábil-financeira fornecida pelas demonstrações contábeis”. Para ser útil a informação deve ser relevante, material e possuir representação fidedigna (características fundamentais). Em complemento, a informação útil pode possuir atributos de melhoria como: comparabilidade; verificabilidade; tempestividade e compreensibilidade (características de melhoria).

Para Hendriksen e Van Breda (2011) a informação contábil só é relevante se for capaz de auxiliar os usuários na tomada de decisão, e para isso, segundo Nascimento et al. (2010) a informação deve ser confiável, livre de viés e possibilitar a comparação com outras informações disponibilizadas em momentos diferentes. No Brasil, os estudos de Sarlo Neto et al. (2005) e Sarlo Neto, Galdi e Dalmácio (2009) estudaram os aspectos da característica da relevância da informação contábil.

$\mathrm{O}$ atributo da relevância se refere à capacidade da informação em fazer diferença nas decisões dos usuários, porém essa diferença só é possível se a informação tiver valor preditivo e/ou valor confirmatório. A predição é obtida se, por meio das informações, for possível predizer resultados futuros. Há valor confirmatório na informação se ela servir de feedback, ou seja, confirmando ou alterando as informações prévias.

A informação possui materialidade se sua omissão ou divulgação distorcida for capaz de influenciar as decisões dos usuários. Porém, de acordo com o disposto no parágrafo QC11 do CPC 00 R1, "não se pode especificar um limite quantitativo uniforme para materialidade ou predeterminar o que seria julgado material para uma situação particular". Sendo assim, esse atributo de qualidade requer julgamento. A Representação fidedigna requer que a informação seja capaz de representar com fidedignidade o fenômeno que se propõe representar, e para isto é necessário que a informação seja completa, neutra e livre de erros.

De acordo com o parágrafo QC13 do CPC 00 R1, a informação para ser completa necessita incluir itens, fatos, circunstâncias, descrições e explicações que contribuam para a compreensão do fenômeno retratado. Neutralidade, por sua vez, "quer dizer que não há viés na direção de um resultado predeterminado" (HENDRIKSEN; VAN BREDA, 2011, p. 100). Ainda de acordo com o CPC 00 R1, em seu parágrafo QC15, a informação livre de erro é aquela que não pode ser distorcida ou manipulada de modo a ser favorável ou desfavorável ao usuário.

Além dessas características fundamentais, a qualidade da informação contábil pode ser melhorada por meio de outros atributos, sendo eles a comparabilidade, a verificabilidade, a tempestividade e a compreensibilidade. No parágrafo QC21 do CPC 00 R1 a comparabilidade é descrita como a característica qualitativa que permite que os usuários identifiquem e compreendam similaridades e diferenças entre itens. A verificabilidade é o atributo que permite aos usuários atestar a representação fidedigna do fenômeno econômico que se propõe representar. Já a tempestividade significa que a informação contábil deve estar disponível no tempo necessário para que os usuários tenham acesso antes de tomarem decisão. Por fim, a informação deve ser divulgada de forma clara e concisa de modo a ser compreensível, porém há fenômenos complexos que não podem ser excluídos dos relatórios e, portanto por vezes, será necessária a ajuda de consultores que contribuam para a compreensão da informação.

\subsection{O analista fundamentalista como intermediário da informação contábil}

A informação financeira permite aos investidores avaliar as oportunidades e o potencial retorno dos recursos aplicados no mercado financeiro (BEYER et al., 2010). De acordo com o CPC 00 R1, as expectativas dos investidores, em termos de retorno dependem da avaliação destes quanto ao montante, tempestividade e incertezas associados aos fluxos de caixa futuros de entrada para a entidade. Consequentemente, este grupo de usuário necessita informações para auxiliá-los no processo decisório.

Porém, de acordo com Iudícibus (2009, p. 111), “os relatórios contábeis são complexos [...] e por isso devem ser analisados exclusivamente por experts em contabilidade e finanças”. Dessa forma, nota-se a importância dos intermediários informacionais, especialmente os analistas de mercado, como influenciadores das decisões realizadas pelos investidores no mercado de capitais. Para Lopes e Martins (2005, p. 75), "Os analistas de mercado de capitais exercem papel fundamental no processo de alocação de recursos nas economias de mercado". Os estudos de Brennan e Subrahmanyam (1995) e Irvine (2003) corroboram essa afirmação, pois, mostram que há associação positiva entre o acompanhamento do analista e a liquidez de mercado. 
Há dois tipos de analistas de mercado, os que realizam a análise gráfica de ações, e os que realizam uma análise fundamentalista das empresas. A análise gráfica, também conhecida como análise técnica, é baseada na construção de gráficos a partir de cotações passadas da empresa, cujo objetivo é sinalizar o comportamento futuro do título, permitindo a identificação de pontos de compra e venda no mercado de ações. Já a análise fundamentalista considera os fundamentos de uma empresa, com base em interpretação de dados e indicadores disponibilizados por essas (MARTINS, 2013). Segundo Dana (2010), a análise fundamentalista considera fatores macro e microeconômicos para avaliar a saúde financeira das empresas, projetar seus resultados futuros e determinar o preço justo para as suas ações. Os fatores macroeconômicos analisados geralmente são a inflação, taxas de juros, câmbio, Produto Interno Bruto (PIB), decisões governamentais, concorrência e setor. Os fatores microeconômicos analisados englobam os resultados da empresa, dividendos, governança corporativa e outros.

Assim, a análise fundamentalista abrange aspectos quantitativos, bem como os aspectos qualitativos, tais como perfil de controladores, executivos, composição do conselho de administração, entre outros. Os analistas fundamentalistas, por meio das análises das demonstrações contábeis, são capazes de fornecer indicadores que permitem a avaliação das ações no mercado, bem como, o retorno a ser obtido no futuro (DANA, 2010).

$\mathrm{O}$ analista de mercado possui diversas habilidades e seu objetivo principal é fazer a avaliação de ativos negociados em Bolsa e recomendações a partir dessa avaliação (HEALY; PALEPU, 2001; BOFF; PROCIANOY; HOPPEN, 2006). O estudo de Gay, Simkins e Turac (2009) sugere que o mercado normalmente acompanha o histórico das previsões dos analistas, ou seja, observam suas recomendações em longo prazo. Irvine (2003) salienta que o mercado interpreta o início da cobertura dos analistas como um sinal positivo.

Portanto, verifica-se que os analistas fundamentalistas são de fato um dos mais importantes usuário da informação contábil e merecem a atenção dos pesquisadores. Considerando que a análise fundamentalista utiliza informações contábeis e financeiras, neste estudo foi dada atenção especial aos analistas fundamentalistas, com a MQIC construída sob a ótica desse grupo de usuários.

\section{PROCEDIMENTOS METODOLÓGICOS}

\subsection{Processo de construção da Métrica de Qualidade da Informação Contábil}

Na construção da Métrica de Qualidade da Informação Contábil (MQIC) foi considerada a percepção dos analistas fundamentalistas, a fim de incluir nela itens cuja relevância fosse apontada por este grupo de usuário das informações. Para tanto, foi empregada a técnica Delphi, a qual, de acordo com Wright e Giovinazzo (2000), consiste na aplicação de questionários a um grupo de especialistas em determinado assunto, em busca de um consenso entre suas respostas. Se necessário, a aplicação do questionário pode ser feita em várias rodadas até que se obtenha a consolidação entre o julgamento de cada indivíduo em relação ao grupo. O processo operacional da técnica Delphi, é apresentado na Figura 1.

Na fase inicial do processo da técnica Delphi houve a aplicação do questionário (com itens para compor a métrica) aos analistas para a construção da MQIC. Tal questionário continha itens extraídos da literatura empírica, normativa e teórica, para que os analistas julgassem se de fato são ou não importantes para composição da métrica. Ao final do questionário havia uma questão aberta para que eles pudessem expor outros itens que julgassem relevantes.

Na primeira aplicação do questionário (primeira rodada Delphi) houve o contato por telefone e e-mail com todas as corretoras cadastradas no site da BM\&FBovespa e algumas empresas de consultoria (Apogeo Investimentos; Bradesco Prime; Maxx Investimentos; Sparta Investimentos; Geral Investimentos e Corretora Bradesco). Os contatos dessas consultorias foram obtidos em seus próprios websites. Também foram enviados e-mails à 77 analistas, cujos contatos foram obtidos nos websites das empresas listadas na Bovespa. No e-mail enviado às corretoras, consultorias e analistas foi anexada uma carta convite para participação na pesquisa. No corpo da carta havia o link para acesso ao questionário. Após a aplicação da primeira rodada Delphi foi feita a análise das respostas dos participantes e a partir disso detectou-se a necessidade de realizar uma segunda rodada Delphi, tendo em vista os novos itens sugeridos por um dos participantes para compor a MQIC. A segunda rodada também foi necessária com o intuito de se obter um maior consenso entre os especialistas sobre os itens avaliados por eles na primeira rodada. Na segunda rodada Delphi um novo questionário foi elaborado e novamente foi enviado o link via e-mail para que os participantes pudessem responder. 


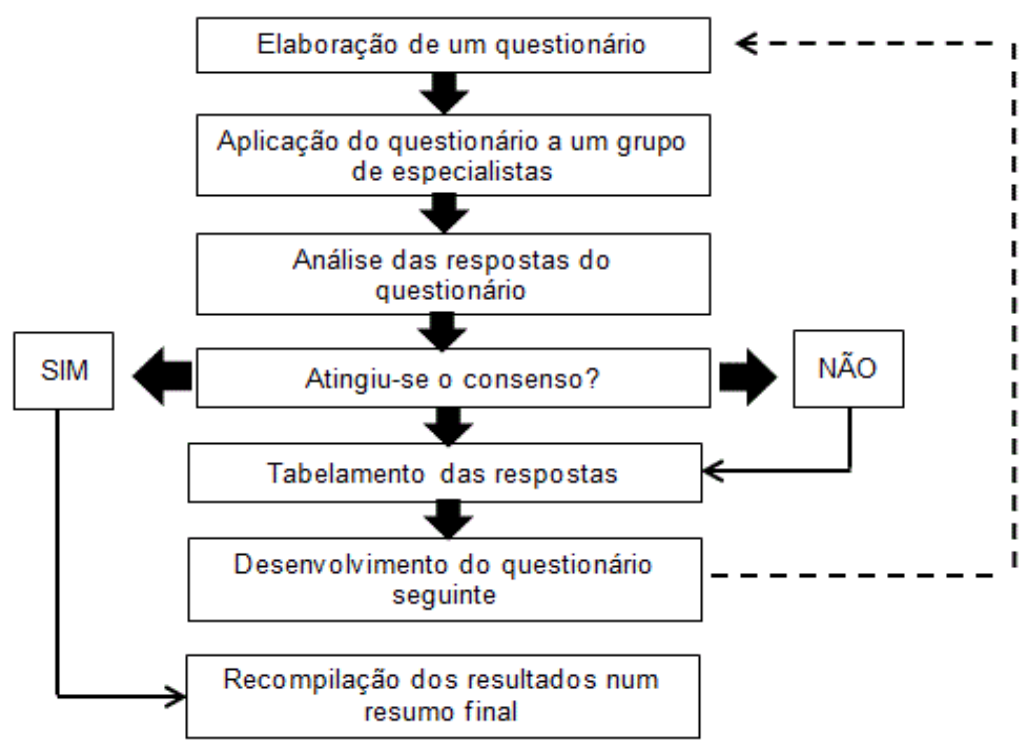

Figura 1. Processo de aplicação da técnica Delphi

Fonte: adaptado de Velez-Pareja (2003).

Após todo o processo de construção, a MQIC foi submetida ao Alfa de Cronbach, a fim de analisar a consistência interna dos itens que a compõe. O coeficiente Alfa de Cronbach é o valor médio de todos os coeficientes de correlação, indicando de forma individual se um item que compõe o instrumento de pesquisa está correlacionado com os demais e caso não esteja, poderá ser eliminado com o intuito de aumentar a confiabilidade do instrumento. Os valores produzidos pelo cálculo do Alfa de Cronbach variam entre 0 e 1 , sendo que acima de 0,7 considera-se confiável o instrumento (MARTINS; THEÓPHILO, 2009).

\subsection{Aplicação da técnica Delphi e Alfa de Cronbach para construção da MQIC}

A aplicação da técnica Delphi ocorreu em dezembro de 2013. Nesta primeira rodada houve a participação de 6 analistas fundamentalistas. Portanto a pesquisa é válida, pois, conforme observam Velez-Pareja (2003), o número mínimo de especialistas a participar da técnica Delphi deve ser cinco (5). O perfil dos especialistas participantes da pesquisa é apresentado no Quadro 1.

\begin{tabular}{c|c|c|c}
\hline Especialista & $\begin{array}{c}\text { Área de formação e grau de } \\
\text { instrução }\end{array}$ & $\begin{array}{c}\text { Tempo de atuação } \\
\text { como analista } \\
\text { fundamentalista }\end{array}$ & Como atua no mercado \\
\hline 1 & Mestrando em Ciências Econômicas & 5 anos & Agente em uma corretora de valores \\
\hline 2 & $\begin{array}{c}\text { Pós graduado em Gestão do Mercado } \\
\text { Financeiro }\end{array}$ & 5 anos & Agente autônomo \\
\hline 3 & Graduação em Ciências Econômicas & 6 anos & Agente em uma corretora de valores \\
\hline 4 & Graduação em Administração & 12 anos & Operador de mesa BM\&Fovespa \\
\hline 5 & Graduação em Engenharia Mecânica & 8 anos & $\begin{array}{c}\text { Agente em uma instituição bancária/ } \\
\text { financeira }\end{array}$ \\
\hline 6 & Graduação em Ciências Econômicas & 6 meses & $\begin{array}{c}\text { Agente em uma instituição bancária/ } \\
\text { financeira }\end{array}$ \\
\hline
\end{tabular}

Quadro 1. Perfil dos participantes da técnica Delphi

Fonte: Dados da pesquisa (2014).

Para aplicação da primeira rodada Delphi foi elaborado um questionário com 20 itens extraídos da literatura empírica, teórica e normativa, cuja essência apresentasse relação com a qualidade da informação 
contábil. Na primeira rodada Delphi, solicitou-se aos especialistas a atribuição de notas, expressando o grau de concordância para cada questão da MQIC, com base na seguinte escala tipo Likert: 1- discordo totalmente; 2 discordo parcialmente; 3 -indiferente; 4 - concordo parcialmente; e 5 - concordo totalmente.

A segunda rodada foi realizada por dois motivos, o primeiro para verificar o grau de concordância dos participantes em relação à 5 itens que foram sugeridos acrescentar à MQIC pelo participante 3, e o segundo, para buscar um maior consenso entre os especialistas em relação aos itens da primeira rodada.

Um segundo questionário foi elaborado e enviado por e-mail aos 6 participantes da primeira rodada, sendo solicitado, então, que eles atribuíssem o seu grau de concordância aos 5 itens acrescentados. Além disso, foi solicitada a comparação de suas notas individuais anteriormente atribuídas com o resultado do grupo, e na sequência, uma reavaliação da nota, caso o participante julgasse necessário. Nenhum dos participantes sugeriu revisar/alterar suas notas e um dos especialistas não participou da segunda rodada. Portanto, os itens 1 a 20 da MQIC foram julgados por 6 especialistas, e os itens 21 a 25 foram julgados por 5 participantes. O resumo dos resultados da rodada Delphi é apresentado na Tabela 1.

Tabela 1. Resumo dos resultados da $1^{\mathrm{a}}$ e $2^{\mathrm{a}}$ rodada Delphi

\begin{tabular}{|c|c|c|c|c|}
\hline \multicolumn{2}{|r|}{ Questões da Métrica de Qualidade da Informação Contábil } & \multirow{2}{*}{$\begin{array}{c}\text { Nota } \\
\text { Média }\end{array}$} & \multirow{2}{*}{$\begin{array}{c}\begin{array}{c}\text { Coeficiente } \\
\text { de Variação }\end{array} \\
23,60\end{array}$} & \multirow{2}{*}{$\begin{array}{c}\text { Análise } \\
\text { Concordância } \\
\text { parcial e média } \\
\text { dispersão }\end{array}$} \\
\hline 1 & $\begin{array}{l}\text { Cobertura das empresas pelos analistas de mercado contribui para } \\
\text { divulgação de informações contábeis com maior qualidade por parte das } \\
\text { empresas. }\end{array}$ & & & \\
\hline 2 & $\begin{array}{l}\text { Um parecer de auditoria limpo indica que as demonstrações contábeis } \\
\text { foram elaboradas de acordo com os princípios e as práticas contábeis, } \\
\text { tornando a informação mais confiável. }\end{array}$ & 3,8 & 30,50 & $\begin{array}{l}\text { Concordância } \\
\text { parcial e alta } \\
\text { dispersão }\end{array}$ \\
\hline 3 & $\begin{array}{l}\text { A presença de membros independentes no conselho de administração } \\
\text { (conselheiros externos) contribui para uma divulgação contábil de maior } \\
\text { qualidade. }\end{array}$ & 4,5 & 12,17 & $\begin{array}{l}\text { Concordância } \\
\text { elevada e baixa } \\
\text { dispersão }\end{array}$ \\
\hline 4 & $\begin{array}{l}\text { Empresas em que os membros do conselho possuem o mandato de um } \\
\text { ano (conforme recomenda o IBGC) tendem a uma divulgação contábil de } \\
\text { maior qualidade. }\end{array}$ & 4,0 & 31,62 & $\begin{array}{l}\text { Concordância } \\
\text { parcial e alta } \\
\text { dispersão }\end{array}$ \\
\hline 5 & $\begin{array}{l}\text { O fato do presidente do conselho de administração e o diretor geral da } \\
\text { empresa serem pessoas diferentes contribui para uma divulgação de } \\
\text { informações contábeis com maior qualidade por parte das empresas. }\end{array}$ & 4,0 & 27,39 & $\begin{array}{l}\text { Concordância } \\
\text { parcial e média } \\
\text { dispersão }\end{array}$ \\
\hline 6 & $\begin{array}{l}\text { O fato de que a empresa esteja sob investigação em curso ou tenha } \\
\text { qualquer tipo de condenação pela CVM no período findo, impacta de } \\
\text { forma negativa a qualidade da divulgação de informações contábeis por } \\
\text { parte das empresas. }\end{array}$ & 2,8 & 46,91 & $\begin{array}{l}\text { Indiferentes e } \\
\text { alta dispersão }\end{array}$ \\
\hline 7 & $\begin{array}{l}\text { A auditoria realizada por uma das big four (PricewaterhouseCoopers, } \\
\text { Deloitte Touche Tohmatsu, KPMG e Ernst \& Young) tem qualidade } \\
\text { superior comparativamente à conduzida por outras firmas de menor porte. }\end{array}$ & 3,8 & 25,65 & $\begin{array}{l}\text { Concordância } \\
\text { parcial e média } \\
\text { dispersão }\end{array}$ \\
\hline 8 & $\begin{array}{l}\text { A reapresentação das demonstrações contábeis, por exigência ou } \\
\text { espontânea, prejudica a confiabilidade da informação apresentada } \\
\text { originalmente. }\end{array}$ & 3,2 & 41,97 & $\begin{array}{l}\text { Indiferentes e } \\
\text { alta dispersão }\end{array}$ \\
\hline 9 & $\begin{array}{l}\text { A divulgação das demonstrações contábeis fora do prazo legal prejudica } \\
\text { a relevância da informação contábil, pois, esta deve estar disponível ao } \\
\text { tomador de decisão antes da perda de sua capacidade de influenciar a } \\
\text { respectiva decisão. }\end{array}$ & 4,0 & 38,73 & $\begin{array}{l}\text { Concordância } \\
\text { parcial e alta } \\
\text { dispersão }\end{array}$ \\
\hline 10 & $\begin{array}{l}\text { A divulgação de informações prospectivas para vendas, lucro e fluxo de } \\
\text { caixa para o exercício findo e exercícios futuros aumenta a relevância da } \\
\text { informação contábil, pois permite aos investidores confirmar ou corrigir } \\
\text { suas expectativas acerca desses indicadores. }\end{array}$ & 3,8 & 19,64 & $\begin{array}{l}\text { Concordância } \\
\text { parcial e média } \\
\text { dispersão }\end{array}$ \\
\hline 11 & $\begin{array}{l}\text { A divulgação de informações de feedback sobre os eventos e transações } \\
\text { de mercado que afetaram a empresa aumenta a relevância da informação } \\
\text { contábil, pois permite aos investidores confirmar ou corrigir suas } \\
\text { expectativas acerca do desempenho econômico e financeiro da empresa. }\end{array}$ & 4,2 & 18,07 & $\begin{array}{l}\text { Concordância } \\
\text { parcial e média } \\
\text { dispersão }\end{array}$ \\
\hline
\end{tabular}


Tabela 1. Resumo dos resultados da $1^{\mathrm{a}}$ e $2^{\mathrm{a}}$ rodada Delphi (continuação)

\begin{tabular}{|c|c|c|c|c|}
\hline \multicolumn{2}{|r|}{ Questões da Métrica de Qualidade da Informação Contábil } & \multirow{2}{*}{$\begin{array}{c}\begin{array}{c}\text { Nota } \\
\text { Média }\end{array} \\
4,2\end{array}$} & \multirow{2}{*}{$\begin{array}{c}\begin{array}{c}\text { Coeficiente } \\
\text { de Variação }\end{array} \\
28,06\end{array}$} & \multirow{2}{*}{$\begin{array}{c}\text { Análise } \\
\text { Concordância } \\
\text { parcial e média } \\
\text { dispersão }\end{array}$} \\
\hline 12 & $\begin{array}{l}\text { A divulgação de aspectos positivos e negativos relacionados ao resultado } \\
\text { do período aumenta a relevância da informação contábil, pois permite aos } \\
\text { investidores confirmar ou corrigir suas expectativas acerca do resultado } \\
\text { do período. }\end{array}$ & & & \\
\hline 13 & $\begin{array}{l}\text { A divulgação de informações explicativas ou justificativas sobre as } \\
\text { oscilações do resultado do período aumenta a relevância da informação } \\
\text { contábil, pois permite aos investidores confirmar ou corrigir suas } \\
\text { expectativas acerca do resultado do período e ainda resultados futuros. }\end{array}$ & 4,0 & 31,62 & $\begin{array}{l}\text { Concordância } \\
\text { parcial e alta } \\
\text { dispersão }\end{array}$ \\
\hline 14 & $\begin{array}{l}\text { A divulgação da remuneração fixa e variável dos executivos e do conselho } \\
\text { de administração aumenta a relevância da informação contábil, pois } \\
\text { permite aos investidores confirmar ou corrigir suas expectativas acerca do } \\
\text { desempenho da entidade e de seus administradores. }\end{array}$ & 4,2 & 31,90 & $\begin{array}{l}\text { Concordância } \\
\text { parcial e alta } \\
\text { dispersão }\end{array}$ \\
\hline 15 & $\begin{array}{l}\text { A divulgação de informações sobre risco e oportunidade de negócios } \\
\text { aumenta a relevância da informação contábil, pois permite aos } \\
\text { investidores confirmar ou corrigir suas expectativas sobre esses itens. }\end{array}$ & 4,3 & 27,95 & $\begin{array}{l}\text { Concordância } \\
\text { elevada e média } \\
\text { dispersão }\end{array}$ \\
\hline 16 & $\begin{array}{l}\text { A divulgação de informações sobre objetivos e estratégias de } \\
\text { gerenciamento de risco aumenta a relevância da informação contábil, pois } \\
\text { permite aos investidores confirmar ou corrigir suas expectativas acerca } \\
\text { dos riscos do negócio. }\end{array}$ & 4,5 & 12,17 & $\begin{array}{l}\text { Concordância } \\
\text { elevada e baixa } \\
\text { dispersão }\end{array}$ \\
\hline 17 & $\begin{array}{l}\text { A divulgação do custo de capital próprio e/ou alguma medida de lucro } \\
\text { econômico (EVA®, valor agregado para o acionista, lucro residual, etc.) } \\
\text { propicia uma melhor análise do desempenho econômico da entidade, } \\
\text { aumentando a relevância da informação contábil. }\end{array}$ & 4,2 & 18,07 & $\begin{array}{l}\text { Concordância } \\
\text { parcial e média } \\
\text { dispersão }\end{array}$ \\
\hline 18 & $\begin{array}{l}\text { A divulgação de informações sobre as escolhas dos princípios e } \\
\text { políticas contábeis proporciona maiores parâmetros para comparação de } \\
\text { informações em diferentes períodos da empresa e desta com informações } \\
\text { de outras empresas. }\end{array}$ & 4,2 & 18,07 & $\begin{array}{l}\text { Concordância } \\
\text { parcial e média } \\
\text { dispersão }\end{array}$ \\
\hline 19 & $\begin{array}{l}\text { A divulgação de informações comparando os resultados do exercício } \\
\text { atual em relação aos anteriores contribui para a qualidade da informação } \\
\text { contábil divulgada pelas empresas. }\end{array}$ & 4,7 & 11,07 & $\begin{array}{l}\text { Concordância } \\
\text { elevada e baixa } \\
\text { dispersão }\end{array}$ \\
\hline 20 & $\begin{array}{l}\text { A divulgação de indicadores financeiros (rentabilidade, liquidez, } \\
\text { endividamento) aumenta a relevância da informação contábil, pois } \\
\text { permite aos investidores confirmar ou corrigir suas expectativas sobre } \\
\text { esses indicadores. }\end{array}$ & 4,8 & 8,45 & $\begin{array}{l}\text { Concordância } \\
\text { elevada e baixa } \\
\text { dispersão }\end{array}$ \\
\hline 21 & $\begin{array}{l}\text { A divulgação da Divida Bruta / Patrimônio Líquido em forma } \\
\text { comparativa, do exercício atual em relação aos anteriores, contribui para a } \\
\text { qualidade da informação contábil divulgada pelas empresas. }\end{array}$ & 4,8 & 9,32 & $\begin{array}{l}\text { Concordância } \\
\text { elevada e baixa } \\
\text { dispersão }\end{array}$ \\
\hline 22 & $\begin{array}{l}\text { A divulgação do EBITDA em forma comparativa, do exercício atual em } \\
\text { relação aos anteriores, contribui para a qualidade da informação contábil } \\
\text { divulgada pelas empresas. }\end{array}$ & 4,8 & 9,32 & $\begin{array}{l}\text { Concordância } \\
\text { elevada e baixa } \\
\text { dispersão }\end{array}$ \\
\hline 23 & $\begin{array}{l}\text { A divulgação da Receita Líquida em forma comparativa, do exercício } \\
\text { atual em relação aos anteriores, contribui para a qualidade da informação } \\
\text { contábil divulgada pelas empresas. }\end{array}$ & 4,8 & 9,32 & $\begin{array}{l}\text { Concordância } \\
\text { elevada e baixa } \\
\text { dispersão }\end{array}$ \\
\hline 24 & $\begin{array}{l}\text { A divulgação do Lucro Líquido em forma comparativa, do exercício } \\
\text { atual em relação aos anteriores, contribui para a qualidade da informação } \\
\text { contábil divulgada pelas empresas. }\end{array}$ & 4,4 & 20,33 & $\begin{array}{l}\text { Concordância } \\
\text { elevada e média } \\
\text { dispersão }\end{array}$ \\
\hline 25 & $\begin{array}{l}\text { A divulgação da Liquidez Corrente em forma comparativa, do exercício } \\
\text { atual em relação aos anteriores, contribui para a qualidade da informação } \\
\text { contábil divulgada pelas empresas. }\end{array}$ & 4,4 & 20,33 & $\begin{array}{l}\text { Concordância } \\
\text { elevada e média } \\
\text { dispersão }\end{array}$ \\
\hline & Resultado Geral & 4,2 & 24,34 & $\begin{array}{l}\text { Concordância } \\
\text { parcial e média } \\
\text { dispersão }\end{array}$ \\
\hline
\end{tabular}

Nota: a Tabela 1 demonstra os resultados da rodada Delphi solicitou-se aos especialistas (analistas fundamentalistas) a atribuição de notas, expressando o grau de concordância para cada questão da MQIC, com base na escala tipo Likert. A segunda coluna apresenta as questões que seriam importante para mensurar a qualidade da informação contábil. A terceira coluna apresenta 
a média das notas atribuídas pelos especialistas (média aritmética). A quarta coluna apresenta o Coeficiente de Variação e a quinta a análise do que representa determinado Coeficiente de Variação.

Fonte: Dados da pesquisa (2014).

Para análise dos resultados da Delphi utilizou-se o Coeficiente de Variação (CV) e a média das notas atribuídas pelos analistas. O Coeficiente de Variação é uma medida de dispersão relativa, e de acordo com Martins (2006, p. 58), se CV < 15\% há baixa dispersão, se CV 15\% $\leq 30 \%$ há média dispersão, se CV $\geq 30 \%$ há elevada dispersão.

De forma geral, os resultados indicaram que houve concordância parcial (média geral de 4,2) entre os participantes e média dispersão (CV de 24,34\%) nas respostas. Porém, os itens 2, 4, 6, 8, 9, 13 e 14 apresentaram coeficientes de variação acima de $30 \%$ sugerindo uma falta de consenso entre os especialistas quanto à importância desses itens na composição da MQIC. Por conta disso, levando em consideração o objetivo proposto neste estudo, esses itens (ver Quadro 2), por não se mostraram importantes na percepção de todos os participantes, foram excluídos da métrica, não fazendo parte da MQIC final. Por fim, observou-se que os itens 19 e 24 questionavam sobre a divulgação do resultado em forma comparativa, e por isso, a decisão foi excluir o item 24, por ter apresentado menor nota atribuída pelos especialistas. Após esses ajustes, a MQIC final foi composta por 17 itens, com a média geral passando a 4,3, indicando concordância elevada sobre os itens que a compõem. Além disso, apesar de o CV ainda indicar uma dispersão média dos dados, ele diminuiu de 24,34\% para 18,40\%.

Após finalizar a construção da MQIC por meio da técnica Delphi, o passo seguinte foi analisar a consistência interna dos itens que compõe a métrica por meio do Alfa de Cronbach. Para o seu cálculo, utilizou-se o software SPSS 15.0, com os resultados demonstrando um Alfa de Cronbach de 0,89, ou seja, a MQIC possui consistência interna.

\begin{tabular}{c|l}
\hline Itens & \multicolumn{1}{c}{ Conteúdo } \\
\hline 2 & $\begin{array}{l}\text { Um parecer de auditoria limpo indica que as demonstrações contábeis foram elaboradas de acordo com os } \\
\text { princípios e as práticas contábeis, tornando a informação mais confiável. }\end{array}$ \\
\hline 4 & $\begin{array}{l}\text { Empresas onde os membros do conselho possuem o mandato de um ano (conforme recomenda o IBGC) } \\
\text { tendem a uma divulgação contábil de maior qualidade. }\end{array}$ \\
\hline 6 & $\begin{array}{l}\text { O fato de que a empresa esteja sob investigação em curso ou tenha qualquer tipo de condenação pela CVM } \\
\text { no período findo impacta de forma negativa a qualidade da divulgação de informações contábeis por parte } \\
\text { das empresas. }\end{array}$ \\
\hline 8 & $\begin{array}{l}\text { A reapresentação das demonstrações contábeis, por exigência ou espontânea, prejudica a confiabilidade da } \\
\text { informação apresentada originalmente. }\end{array}$ \\
\hline 13 & $\begin{array}{l}\text { A divulgação das demonstrações contábeis fora do prazo legal prejudica a relevância da informação } \\
\text { contábil, pois esta deve estar disponível ao tomador de decisão antes da perda de sua capacidade de } \\
\text { influenciar a respectiva decisão. }\end{array}$ \\
\hline 14 & $\begin{array}{l}\text { A divulgação de informações explicativas ou justificativas sobre as oscilações do resultado do período } \\
\text { aumenta a relevância da informação contábil, pois permite aos investidores confirmar ou corrigir suas } \\
\text { expectativas acerca do resultado do período e ainda resultados futuros. }\end{array}$ \\
\hline $\begin{array}{l}\text { A divulgação da remuneração fixa e variável dos executivos e do conselho de administração aumenta a } \\
\text { relevância da informação contábil, pois permite aos investidores confirmar ou corrigir suas expectativas } \\
\text { acerca do desempenho da entidade e de seus administradores. }\end{array}$ \\
\hline
\end{tabular}

Quadro 2. Itens excluídos da MQIC após realização da técnica Delphi

Fonte: Dados da pesquisa (2014).

\section{RESULTADOS}

\subsection{Apresentação da MQIC em sua forma final}

Conforme explicado no item de construção da métrica de qualidade da informação contábil, neste estudo chegou-se à métrica apresentada na Tabela 2. Os componentes 14 a 17 se referem àqueles que os especialistas sugeriram incluir na métrica durante o processo de aplicação da técnica Delphi. Tais itens não representam informações tratadas pela contabilidade, porém estão diretamente a ela relacionadas, pois em seu cálculo utiliza-se dados extraídos dos relatórios contábeis. Dessa forma considerou-se relevante adicioná-los à métrica. 
Tabela 2. Métrica de Qualidade da Informação Contábil (MQIC) em sua forma final

\begin{tabular}{|c|c|c|c|c|}
\hline & Componente & $\begin{array}{l}\text { Pontuação } \\
\text { máxima do } \\
\text { componente }\end{array}$ & Peso & $\begin{array}{l}\text { Nota } \\
\text { máxima do } \\
\text { componente }\end{array}$ \\
\hline \multirow{4}{*}{ 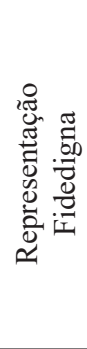 } & 1 - A empresa possui cobertura dos analistas de mercado? & 1 & 4,2 & 4,2 \\
\hline & $\begin{array}{l}2 \text { - O conselho de administração possui a presença de membros } \\
\text { independentes (conselheiros externos)? }\end{array}$ & 1 & 4,5 & 4,5 \\
\hline & $\begin{array}{l}3 \text { - O presidente do conselho de administração e o diretor geral da } \\
\text { empresa são pessoas diferentes? }\end{array}$ & 1 & 4,0 & 4,0 \\
\hline & $\begin{array}{l}4 \text { - A auditoria é realizada por uma das big four } \\
\text { (PricewaterhouseCoopers, Deloitte Touche Tohmatsu, KPMG e Ernst } \\
\text { \& Young)? }\end{array}$ & 1 & 3,8 & 3,8 \\
\hline \multirow{6}{*}{$\begin{array}{l}\frac{\pi}{0} \\
\frac{\pi}{10} \\
\frac{d}{2} \\
\frac{0}{2}\end{array}$} & $\begin{array}{l}5 \text { - A empresa divulga informações prospectivas para vendas, lucros e } \\
\text { fluxo de caixa? }\end{array}$ & 3 & 3,8 & 11,5 \\
\hline & $\begin{array}{l}6 \text { - A empresa divulga informações de feedback sobre os eventos e } \\
\text { transações de mercado que afetaram a empresa no período findo? }\end{array}$ & 1 & 4,2 & 4,2 \\
\hline & $\begin{array}{l}7 \text { - A empresa divulga aspectos positivos e negativos relacionados ao } \\
\text { resultado do período? }\end{array}$ & 2 & 4,2 & 8,3 \\
\hline & $\begin{array}{l}8 \text { - A empresa divulga informações sobre risco e oportunidade de } \\
\text { negócios? }\end{array}$ & 2 & 4,3 & 8,7 \\
\hline & $\begin{array}{l}9 \text { - A empresa divulga informações sobre objetivos e estratégias de } \\
\text { gerenciamento de risco? }\end{array}$ & 1 & 4,5 & 4,5 \\
\hline & $\begin{array}{l}10 \text { - A empresa divulga o custo de capital próprio e/ou alguma medida } \\
\text { de lucro econômico (EVA } \AA \text {, valor agregado para o acionista, lucro } \\
\text { residual)? }\end{array}$ & 1 & 4,2 & 4,2 \\
\hline \multirow{8}{*}{ 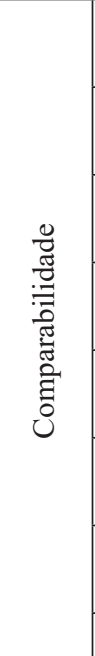 } & $\begin{array}{l}11 \text { - A empresa divulga informações sobre as escolhas dos princípios } \\
\text { e políticas contábeis? }\end{array}$ & 1 & 4,2 & 4,2 \\
\hline & $\begin{array}{l}12 \text { - A empresa divulga os resultados do exercício em forma } \\
\text { comparativa (do exercício atual em relação aos anteriores)? }\end{array}$ & 1 & 4,7 & 4,7 \\
\hline & $\begin{array}{l}13 \text { - A empresa divulga indicadores financeiros (rentabilidade, } \\
\text { liquidez, endividamento, EBITDA)? }\end{array}$ & 4 & 4,8 & 19,3 \\
\hline & $\begin{array}{l}14 \text { - A empresa divulga a Dívida Bruta / Patrimônio Líquido em } \\
\text { forma comparativa (do exercício atual em relação aos anteriores)? }\end{array}$ & 1 & 4,8 & 4,8 \\
\hline & $\begin{array}{l}15 \text { - A empresa divulga o EBITDA em forma comparativa (do } \\
\text { exercício atual em relação aos anteriores)? }\end{array}$ & 1 & 4,8 & 4,8 \\
\hline & $\begin{array}{l}16 \text { - A empresa divulga a Receita Líquida em forma comparativa (do } \\
\text { exercício atual em relação aos anteriores)? }\end{array}$ & 1 & 4,8 & 4,8 \\
\hline & $\begin{array}{l}17 \text { - A empresa divulga a Liquidez Corrente em forma comparativa } \\
\text { (do exercício atual em relação aos anteriores)? }\end{array}$ & 1 & 4,4 & 4,4 \\
\hline & Pontuação máxima total dos componentes & & & 104,8 \\
\hline
\end{tabular}

Nota: a Tabela 2 demonstra a métrica que resultou da aplicação da Técnica Delphi. Na segunda coluna apresenta-se as questões que compõem a métrica. A nota máxima do componente (questões da métrica) é apresentada na quinta coluna, cujo resultado foi obtido pela multiplicação da pontuação máxima de cada componente pelo seu respectivo peso.

Fonte: Dados da pesquisa (2014).

A MQIC é composta por 17 componentes (perguntas), cujas respostas espera-se positivas. Para cada componente com resposta positiva atribui-se um (1) ponto para a empresa, caso contrário atribui-se pontuação zero (0). Os componentes 5, 7, 8 e 13 possuem pontuação acima de um (1), por considerarem mais de uma informação, por exemplo, no componente 5 serão atribuído três (3) pontos para a companhia que divulgar informações prospectivas para vendas, lucros e fluxo de caixa. Isto é, para cada uma dessas informações divulgadas, a empresa receberá um (1) ponto.

Além da pontuação atribuída para cada componente, atribuiu-se o peso de acordo com o consenso dos analistas alcançado com a técnica Delphi, ou seja, por meio da atribuição de notas dos analistas aos componentes utilizando a escala tipo Likert: 1- discordo totalmente; 2 - discordo parcialmente; 3 - indiferente; 4 - concordo 
parcialmente; e 5 - concordo totalmente. Dessa forma, o peso para cada componente foi atribuído com base na nota média do grau de concordância dado pelos analistas. A atribuição de tal peso se justifica, pois, busca-se valorizar para mais ou para menos os itens da métrica conforme a percepção dos analistas, ou seja, todos os itens foram importantes para os analistas, porém alguns itens se demonstraram mais importantes do que outros. A pontuação de cada componente da MQIC é resultado da multiplicação da pontuação obtida pela empresa no componente com o peso do componente. A MQIC é calculada conforme demonstrado na Equação 1:

$$
M Q I C_{x}=\frac{\sum_{k=1}^{n} p_{x k} w_{k}}{\sum_{k=1}^{n} p_{k} w_{k}} \times 100
$$

Em que,

$M Q I C_{x}$ é a Métrica de Qualidade da Informação Contábil da empresa $x$;

$n$ é a quantidade de componentes $k$;

$p_{x k}$ é a pontuação $p$ obtida pela empresa $x$ no componente $k$;

$w_{k}$ é peso $w$ do componente $k$;

$p_{k}$ é a pontuação $p$ máxima do componente $k$.

A pontuação máxima total dos componentes da MQIC é 104,8. Porém, visando facilitar a interpretação, a pontuação obtida no somatório dos componentes é transformada para uma escala de 0 à 100 . Assim, assume-se que quanto maior for a pontuação da MQIC em uma escala que varia de 0 (zero) a 100 (cem), melhor a qualidade da informação contábil divulgada pela empresa. Visando exemplificar o cálculo da MQIC, utilizou-se as informações divulgadas pela empresa Cielo S.A. para o ano de 2013. A escolha da Cielo S.A ocorreu de forma aleatória, com o objetivo de simplesmente demonstrar o cálculo da MQIC e apresentar como exemplo uma breve análise dos resultados a partir da coleta da métrica.

Tabela 3. Exemplo de aplicação da MQIC

\begin{tabular}{|c|c|c|c|}
\hline \multicolumn{4}{|l|}{ Empresa: Cielo S.A. - 2013} \\
\hline Componente (conforme definidos na tabela 2) & $\begin{array}{c}\text { Pontuação } \\
\text { obtida no } \\
\text { componente }\end{array}$ & Peso & $\begin{array}{c}\text { Nota } \\
\text { obtida no } \\
\text { componente }\end{array}$ \\
\hline 1 - A empresa possui cobertura dos analistas de mercado? & 1 & 4,2 & 4,2 \\
\hline $\begin{array}{l}2 \text { - O conselho de administração possui a presença de membros independentes } \\
\text { (conselheiros externos)? }\end{array}$ & 1 & 4,5 & 4,5 \\
\hline $\begin{array}{l}3 \text { - O presidente do conselho de administração e o diretor geral da empresa são } \\
\text { pessoas diferentes? }\end{array}$ & 1 & 4,0 & 4,0 \\
\hline $\begin{array}{l}4 \text { - A auditoria é realizada por uma das big four (PricewaterhouseCoopers, Deloitte } \\
\text { Touche Tohmatsu, KPMG e Ernst \& Young)? }\end{array}$ & 1 & 3,8 & 3,8 \\
\hline $\begin{array}{l}5 \text { - A empresa divulga informações prospectivas para vendas, lucros e fluxo de } \\
\text { caixa? }\end{array}$ & 0 & 3,8 & 0 \\
\hline $\begin{array}{l}6 \text { - A empresa divulga informações de feedback sobre os eventos e transações de } \\
\text { mercado que afetaram a empresa no período findo? }\end{array}$ & 0 & 4,2 & 0 \\
\hline $\begin{array}{l}7 \text { - A empresa divulga aspectos positivos e negativos relacionados ao resultado do } \\
\text { período? }\end{array}$ & 0 & 4,2 & 0 \\
\hline 8 - A empresa divulga informações sobre risco e oportunidade de negócios? & 1 & 4,3 & 4,3 \\
\hline $\begin{array}{l}9 \text { - A empresa divulga informações sobre objetivos e estratégias de gerenciamento } \\
\text { de risco? }\end{array}$ & 0 & 4,5 & 0 \\
\hline $\begin{array}{l}10 \text { - A empresa divulga o custo de capital próprio e/ou alguma medida de lucro } \\
\text { econômico (EVA®, valor agregado para o acionista, lucro residual)? }\end{array}$ & 0 & 4,2 & 0 \\
\hline $\begin{array}{l}11 \text { - A empresa divulga informações sobre as escolhas dos princípios e políticas } \\
\text { contábeis? }\end{array}$ & 1 & 4,2 & 4,2 \\
\hline $\begin{array}{l}12 \text { - A empresa divulga os resultados do exercício em forma comparativa (do } \\
\text { exercício atual em relação aos anteriores)? }\end{array}$ & 1 & 4,7 & 4,7 \\
\hline $\begin{array}{l}13 \text { - A empresa divulga indicadores financeiros (rentabilidade, liquidez, } \\
\text { endividamento, EBITDA)? }\end{array}$ & 3 & 4,8 & 14,4 \\
\hline
\end{tabular}


Tabela 3. Exemplo de aplicação da MQIC (continuação)

\begin{tabular}{|c|c|c|c|}
\hline \multicolumn{4}{|l|}{ Empresa: Cielo S.A. - 2013} \\
\hline Componente (conforme definidos na tabela 2) & $\begin{array}{c}\text { Pontuação } \\
\text { obtida no } \\
\text { componente }\end{array}$ & Peso & $\begin{array}{c}\text { Nota } \\
\text { obtida no } \\
\text { componente }\end{array}$ \\
\hline $\begin{array}{l}14 \text { - A empresa divulga a Dívida Bruta / Patrimônio Líquido em forma } \\
\text { comparativa (do exercício atual em relação aos anteriores)? }\end{array}$ & 1 & 4,8 & 4,8 \\
\hline $\begin{array}{l}15 \text { - A empresa divulga o EBITDA em forma comparativa (do exercício atual em } \\
\text { relação aos anteriores)? }\end{array}$ & 1 & 4,8 & 4,8 \\
\hline $\begin{array}{l}16 \text { - A empresa divulga a Receita Líquida em forma comparativa (do exercício } \\
\text { atual em relação aos anteriores)? }\end{array}$ & 1 & 4,8 & 4,8 \\
\hline $\begin{array}{l}17 \text { - A empresa divulga a Liquidez Corrente em forma comparativa (do exercício } \\
\text { atual em relação aos anteriores)? }\end{array}$ & 0 & 4,4 & 0 \\
\hline Pontuação obtida nos componentes & & & 58,5 \\
\hline
\end{tabular}

Nota: a Tabela 3 apresenta os resultados da métrica para a Cielo S.A no ano de 2013.

Fonte: Dados da pesquisa (2014).

Ao aplicar a Equação 1, obtém-se:

$$
M Q I C_{\text {Cielo2013 }}=\frac{\sum_{k=1}^{17} p_{\text {Cielo2013k}} w_{k}}{\sum_{k=1}^{17} p_{k} w_{k}} \times 100 \therefore M Q I C_{\text {Cielo } 2013}=\frac{58,5}{104,8} \times 100 \therefore M Q I C_{\text {Cielo } 2013} \cong 55,82
$$

Em relação ao ano de 2013, a Cielo S.A. apresentou uma MQIC de 55,82, o que significa que a empresa divulgou, nesse ano, 55,82\% dos itens que compõem a métrica. Entre os componentes da MQIC que a empresa não divulgou estão as informações prospectivas para vendas, lucros e fluxo de caixa; feedback sobre os eventos e transações de mercado que afetaram a empresa no período findo; aspectos positivos e negativos relacionados ao resultado do período; objetivos e estratégias de gerenciamento de risco; o custo de capital próprio e/ou alguma medida de lucro econômico (EVA ${ }^{\circledR}$, valor agregado para o acionista, lucro residual) e a Liquidez Corrente em forma comparativa.

Portanto, o cálculo da MQIC de uma empresa para um determinado período permite avaliar a qualidade das informações por ela divulgadas ao mercado, possibilitando comparações com seu histórico de divulgação, bem como em relação à outras empresas.

\section{CONSIDERAÇÕES FINAIS}

A informação contábil, devido à sua utilidade para os analistas de mercado, possui relevância no mercado de capitais por influenciar as decisões de investimentos. $\mathrm{O}$ analista de mercado utiliza informações públicas para fazer suas previsões e recomendações de investimentos. No entanto, suas previsões dependem da qualidade da informação divulgada. Neste contexto Beest, Braam e Boelens (2009) argumentam que na literatura contábil há somente medidas indiretas para medir a qualidade da informação. Além disso, Malaquias e Oliveira Neto (2011) consideram importante levar em conta a percepção dos usuários da informação quando da construção de instrumentos de coleta de dados, pois isso implicaria em resultados mais robustos.

O objetivo deste estudo consistiu na elaboração de uma Métrica de Qualidade da Informação Contábil (MQIC) sob a ótica de analistas fundamentalistas. Para isso foi utilizada a técnica Delphi com aplicação de um questionário elaborado a partir da literatura empírica, normativa e teórica sobre qualidade da informação contábil.

Os resultados do estudo possibilitaram construir uma MQIC com 17 componentes, representativos das características qualitativas representação fidedigna, relevância e comparabilidade, cuja nota varia numa escala de 0 a 100, sendo que, quanto maior for a pontuação da MQIC, melhor a qualidade da informação contábil divulgada pela empresa. A média geral da métrica final é de 4,3, indicando uma concordância elevada dos analistas fundamentalistas sobre os itens que compõem a MQIC. Além disso o Coeficiente de Variação é de 18,4\% o que indica uma dispersão média dos dados. Os resultados do Alfa de Cronbach mostram que a MQIC possui consistência interna de 0,890 . 
O estudo pode ser relevante por apresentar como contribuição a construção e validação de uma métrica capaz de captar a qualidade das informações contábeis sob a ótica de analistas fundamentalistas, ou seja, externos às empresas. A métrica, portanto, poderá ser utilizada pelos próprios analistas de mercado, bem como investidores, credores e demais usuários das informações divulgadas ao mercado no processo de tomada de decisões. Tais usuários poderão se beneficiar da métrica ao utilizá-la como ferramenta para medir a qualidade das informações contábeis. Acredita - se também que a métrica poderá ser utilizada por pesquisadores em estudos que busquem verificar a relação da qualidade das informações contábeis com o valor de mercado das empresas, comportamento das ações, e liquidez dos títulos, bem como outras questões relacionadas à expectativas dos investidores.

Uma das limitações da pesquisa consiste no fato de ter considerado apenas a percepção dos analistas fundamentalistas enquanto usuários da informação contábil, sendo que há outros grupos de usuários. Outra limitação diz respeito ao grupo pequeno de analistas que participaram da pesquisa, apesar dos vários contatos realizados junto a esses profissionais. Os achados da pesquisa ainda são limitados pela falta de construtos relacionados às características qualitativas da tempestividade, devido a falta de consenso dos especialistas sobre o único item proposto para compor a MQIC; da compreensibilidade e da materialidade, sendo que em relação a esses dois itens em função da dificuldade de se encontrar fatores que os representem.

Em estudos futuros, sugere-se a realização de comparação entre a percepção dos analistas de mercado com outros usuários da contabilidade e ainda a busca de construtos que permitam mensurar as demais características qualitativas que não foram contempladas nesta pesquisa, bem como a aplicação da MQIC a fim de pontuar a qualidade da informação contábil divulgada pelas empresas.

\section{REFERÊNCIAS}

BALL, R.; SHIVAKUMAR, L. Earnings quality in UK private firms: comparative loss recognition timeliness. Journal of Accounting and Economics. v. 39, n.1, p. 83-128, fev. 2005.

BEEST, F. V.; BRAAM, G.; BOELENS, S. Quality of financial reporting: measuring qualitative characteristics. NiCE Working Paper 09-108, abr. 2009. Disponível em: <https://www.google.com.br/?gws_rd=cr\&ei=A29 XUquFApTd4AOh7oD4DA\#psj=1\&q=Quality+of+Financial+Reporting:+measuring+qualitative+character istics>. Acesso em: 25 mai. 2013.

BEYER, A.; COHEN, D. A.; LYS, T. Z.; WALTHER, B. R. The financial reporting environment: review of the recent literature. Journal of Accounting and Economics, v. 50, n. 2-3, p. 296-343, dez. 2010.

BIDDLE, G.C.; HILARY, G. Accounting quality and firm-level capital investment. The Accounting Review, v.81, n.5, p.963-982, out. 2006.

BOFF, L. H.; PROCIANOY, J. L.; HOPPEN, N. O uso de informações por analistas de investimento na avaliação de empresas: à procura de padrões. Revista de Administração Contemporânea, v. 10, n. 4, p. 169-192, out./ dez. 2006.

BRENNAN, M.; SUBRAHMANYAM, A. Investment analysis and price formation in securities markets. Journal of Financial Economics, v. 38, n. 3, p. 361-381, jul. 1995.

CARVALHO, F. L. Qualidade das informações contábeis, restrição financeira e decisões de investimento: evidências para a América Latina. Tese (Doutorado em Engenharia da Produção) - Programa de PósGraduação em Engenharia de Produção, Universidade de São Paulo, São Carlos, 2012.

COMITÊ DE PRONUNCIAMENTOS CONTÁBEIS. Pronunciamento Técnico CPC 00 (R1): Estrutura Conceitual para Elaboração e Divulgação de Relatório Contábil-Financeiro. Disponível em: $<$ http:// www.cpc.org.br/mostraOrientacao.php?id=14>. Acesso em: 20 abr. 2013.

DANA, S. Como funciona a análise fundamentalista de ações: entenda como os investidores analisam balanços e fazem contas para avaliar se determinada empresa está ou não barata. Exame.com, 06 jul. 2010. Disponível em: <http:/exame.abril.com.br/seu-dinheiro/acoes/noticias/como-funciona-analise-fundamentalista-acoes-576374>. Acesso em: 20 dez. 2013. 
DYE, R. A. An evaluation of "essays on disclosure" and the disclosure literature in accounting. Journal of Accounting and Economics, n. 32, n. 1-3, p. 181-235, dez. 2001.

FISCHER, P.E.; STOCKEN, P.C. Analyst information acquisition and communication. The Accounting Review, v. 85 , n. 6, p. 1985-2009, nov. 2010.

FRANCIS, J.; HANNA, J. D.; PHILBRICK, D. R. Management communications with securities analysts. Journal of Accounting and Economics, v. 24, n. 3, p. 363-394, dez. 1997.

FRANCIS, J.; LAFOND, R.; OLSSON, P. M.; SCHIPPER, K. Costs of equity and earnings attributes. The Accounting Review, v. 79, n. 4, p. 967-1010, out. 2004.

GAY, G. D.; SIMKINS, B. J.; TURAC, M. Analyst forecasts and price discovery in futures markets: the case of natural gas storage. The Journal of Futures Markets, v. 29, n. 5, p. 451-477, mai. 2009.

HEALY, P. M.; PALEPU, K. G. Information asymmetry, corporate disclosure, and the capital markets: a review of the empirical disclosure literature. Journal of Accounting and Economics. v. 31. N. 1-3, p.405-440, set. 2001 .

HENDRIKSEN, E. S.; VAN BREDA, M. F. Teoria da contabilidade. São Paulo: Atlas, 2011.

IRVINE, P. J. The incremental impact of analyst initiation of coverage. Journal of Corporate Finance, v. 9, n. 4, p. 431-451, set. 2003 .

IUDÍCIBUS, S de. Teoria da contabilidade. 9. ed. São Paulo: Atlas, 2009.

KAM, V. Accounting theory. Illinois: IE-WILEY, 1990.

LOPES, A. B.; MARTINS, E. Teoria da Contabilidade: uma nova abordagem. São Paulo: Atlas, 2005.

MALAQUIAS, R. F; OLIVEIRA NETO, O. J. Integração entre focus group e nível de evidenciação: discussões e propostas para o avanço metodológico da pesquisa em finanças e contabilidade. In: Semead - Seminários em Administração, 14, São Paulo, Anais eletrônicos... São Paulo: USP, 2011. Disponível em: <http://www.ead. fea.usp.br/semead/14semead/resultado/an_resumo.asp?cod_trabalho=478>. Acesso em: 02 abr. 2014.

MARTINS, G. A. Estatística geral e aplicada. São Paulo: Atlas, 2006.

MARTINS, L. A importância de se utilizar a analise técnica de ações (análise gráfica) para investir em ações? Seuconsultorfinanceiro.com.br, 2013. Disponível em: <http://www.seuconsultorfinanceiro.com.br/artigos_ investimento.php?secao $=43 \&$ parametro $=1836>$. Acesso em: 20 dez. 2013.

MARTINS, G. A.; THEÓPHILO, C. R. Metodologia da investigação científica para ciências sociais aplicadas. 2. ed. São Paulo: Atlas, 2009.

NASCIMENTO, E. M.; GUERRA, M.; FERNANDES, N. A. C.; COLAUTO, R. D. Divulgação de informações financeiras de companhias siderúrgicas e metalúrgicas brasileiras. RCO - Revista de Contabilidade e Organizações, v. 4, n. 10, p. 3-24, set./dez. 2010.

SARLO NETO, A.; GALDI, F. C.; DALMÁCIO, F. Z. Uma pesquisa sobre o perfil das ações brasileiras que reagem à publicação dos resultados contábeis. RCO - Revista de Contabilidade e Organização, v. 3, n. 6, p. 22- 40, mai./ago. 2009.

SARLO NETO, A.; LOSS, L. T.; ARIDELMO J. C.; LOPES, A. B. O diferencial no impacto dos resultados contábeis nas ações ordinárias e preferenciais no mercado brasileiro. Revista Contabilidade \& Finanças, v. 16, n. 37, p. 46-58, jan./abr. 2005.

SILVA, R. L. M. Divulgação de informações e liquidez de ações: evidências do setor de siderurgia e metalurgia 
do Brasil. Dissertação (Mestrado em Ciências Contábeis) - Programa de Pós-Graduação em Controladoria e Contabilidade, Universidade de São Paulo, Ribeirão Preto, 2009.

TAKAMATSU, R. T.; LAMOUNIER, W. M.; COLAUTO, R. D. Impactos da divulgação de prejuízos nos retornos de ações de companhias participantes do Ibovespa. Revista Universo Contábil, v. 4, n. 1, p. 46-63, jan./mar. 2008.

VELEZ-PAREJA, I. The Delphi Method (El Metodo Delphi). SSRN Working Paper, jun. 2003. Disponível em: $<$ http://papers.ssrn.com/sol3/papers.cfm?abstract_id=420040>. Acesso em: 03 abr. 2014.

VERRECCHIA, R. E. Essays on disclosure. Journal of Accounting and Economics, n. 32, n. 1-3, p. 97-180, dez. 2001.

WRIGHT, J. T. C.; GIOVINAZZO, R. A. Delphi - uma ferramenta de apoio ao planejamento prospectivo. Caderno de Pesquisas em Administração, v. 1, n. 12, p. 54-65, 2000.

YAMAMOTO, M. M.; SALOTTI, B. M. Informação contábil: estudos sobre a sua divulgação no mercado de capitais. São Paulo: Atlas, 2006. 